Сувалова Татьяна Викторовна

канд. экон. наук, ФГБОУ ВО «Государственный университет управления», г. Москва, Российская Федерация ORCID: 0000-0001-7110-7698

e-mail:suvalova.t@yandex.ru

Масюкова Полина Олеговна студент магистратуры, ФГБОУ ВО «Государственный университет управления», г. Москва, Российская Федерация e-mail:masukovap@gmail.com

\section{Suvalova Tatiana}

Candidate of Economic Sciences, State University of Management, Moscow, Russia ORCID: 0000-0001-7110-7698

e-mail:suvalova.t@yandex.ru

\section{Masyukova Polina}

Student, State University of Management, Moscow, Russia

e-mail:masukovap@gmail.com

\section{АКТУАЛЬНЫЕ ИНСТРУМЕНТЫ УПРАВЛЕНИЯ СОЦИАЛЬНЫМ РАЗВИТИЕМ ПЕРСОНАЛА КРУПНЫХ КОМПАНИЙ}

\begin{abstract}
Аннотация. Целью исследования является анализ эффективности инструментов управления сочиальным развитием персонала. В статье рассмотрена сущность социальной политики, сочиальные гарантии, сочиальные программы. Обоснована важность управления соииальным развитием персонала для крупных компаний, выделены функиии и задачи социального управления. Реализация рассмотренных функций позволит привлечь и удержать более квалифицированных и талантливых сотрудников, улучшить эффективность профессионального взаимодействия в коллективе $u$, соответственно, повысить эффективность работы персонала и предприятия в целом. Отмечено влияние уровня планирования сочиальных программ на повышение уровня лояльности работников к организации, рост производительности труда, сочиильной активности, творчества, рационализации деятельности. Аргументирована роль управления сочиальным развитием персонала, социальных условий труда и социальной инфраструктуры. Выделены важнейшие инструменты управления сочиальным развитием персонала предприятия.
\end{abstract}

Ключевые слова: лояльность, мотивация, организачия, персонал, социальная инфраструктура, социальное развитие, сочиально-психологический климат, социальные условия труда, управление.

Цитирование: Сувалова Т.В., Масюкова П.О. Актуальные инструменты управления социальным развитием персонала крупных компаний//Вестник университета. 2020. № 4. С. 19-22.

\section{CURRENT TOOLS FOR MANAGING SOCIAL DEVELOPMENT OF LARGE COMPANIES' PERSONNEL}

\begin{abstract}
The aim of the study is to analyse the effectiveness of personnel social development management tools. The essence of social policy, social guarantees, social programs has been considered in the article. The importance of managing social development of personnel for large companies has been substantiated, the functions and tasks of social management have been highlighted. The implementation of the functions considered will help to attract and retain more qualified and talented employees, improve the effectiveness of professional interaction in the team and, accordingly, increase the efficiency of the staff and the enterprise as a whole.The influence of the level of planning social programs on increasing the level of employee loyalty to the organization, the growth of labor productivity, social activity, creativity, rationalization of activities have been noted. The role of management of the personnel social development, the social working conditions and social infrastructure has been argued. The most important tools for managing social development of enterprise personnel have been highlighted.
\end{abstract}

Keywords: entity, loyalty, management, motivation, personnel, social development, social infrastructure, social working conditions, socio-psychological climate.

For citation: Suvalova T.V., Masyukova P.O. (2020) Current tools for managing social development of large companies' personnel. Vestnik universiteta. I. 4, pp. 19-22. DOI: 10.26425/1816-4277-2020-4-19-22

Современное российское общество переживает динамичное преобразование социально-экономических систем, что повышает роль социального развития персонала в производственных и управленческих процессах любого предприятия. Такая ситуация создает предпосылки для изменения принципов управления персоналом и доказывает важность социального развития сотрудников предприятия. Необходимость социального

( С Сувалова Т.В., Масюкова П.О., 2020. Статья доступна по лицензии Creative Commons «Attribution» («Атрибуция») 4.0. всемирная (http://creativecommons.org/licenses/by/4.0/).

The Author(s), 2020. This is an open access article under the CC BY 4.0 license (http://creativecommons.org/licenses/by/4.0/).

(c) (i) 
развития персонала обоснована также и тем, что от эффективного управления зависит как уровень производительности труда, так и экономические показатели деятельности предприятия.

Грамотная социальная политика обеспечивает повышение производительности труда, сокращение операционных затрат, укрепляет репутацию и имидж предприятия, увеличивает привлекательность работодателя перед потенциальными работниками.

Объем социальных гарантий, которые может предложить организация, напрямую зависят от ее экономического положения. Несмотря на то, что у многих предприятий имеется экономическая возможность, они не готовы вкладывать ресурсы в развитие своей социальной сферы деятельности. Основная причина этого это отсутствие расчета экономического эффекта социальных программ.

Социальные программы являются одним из направлений реализации социальной стратегии развития предприятия, которое задействует социальные факторы в качестве эффективного механизма повышения производительности труда работников. Основными целями любых социальных программ являются: привлечение и сохранение высококвалифицированных сотрудников, стимулирование производительности и результативности труда, укрепление трудовой дисциплины, формирование корпоративной культуры и лояльности к руководству.

Вопросы управления социальным развитием персонала достаточно широко освещены в научных работах ученых: Ю. П. Соболева, Т. В. Карпова; К. К. Федотова, Т. С. Демченко; А. В. Неверов; М. А. Эскиев, М. Р. Айсханов; С. В. Мясникова, А. А. Конарева и пр. Однако в последнее время, в условиях увеличения актуальности социального менеджмента и повышения его роли в обеспечении конкурентоспособности предприятия необходимость дальнейших исследований в данном направлении возрастает.

Целью данного исследования является обоснование важности управления социальным развитием персонала.

Чем крупнее компания, тем более актуальными становятся для ее руководства вопросы управления социальным развитием персонала. Несмотря на финансово-экономические трудности российской экономики и современных корпораций, генералитет признает персонал ключевым ресурсом - стратегическим ядром, определяющим успех компании в любой отрасли. От социальной политики зависит уровень отдачи ключевых сотрудников, их результативность и продуктивность, мотивация на успех, лояльность к компании. Социальные инструменты направлены на вовлечение персонала в процесс участия в принятии управленческих и производственных решений.

Под социальными инструментами правомерно понимать совокупность всех услуг, предоставляемых компанией своим сотрудникам, а также членам их семей, не включая оплату труда. В зависимости от роли и ранга сотрудника набор услуг видоизменяется и расширяется. Возрастает роль социального планирования. Социальные инструменты приобретают системный характер, нацеленный на реализацию стратегии и миссии компании.

В крупных компаниях планы социального развития реализуются структурными подразделениями службами по управлению персоналом, отдельно выделяют и службу по социальному развитию. Управление социальным развитием крупных компаний сегодня выделяется в качестве самостоятельной социальной стратегии, тесно связанной с финансово-экономической, маркетинговой, экологической, производственнохозяйственной политиками.

Общественная полезность компаний, ее социальная эффективность наряду с экономической, оценивается по масштабу и совокупности предоставляемых социальных программ.

Отметим, что под социальным развитием персонала правомерно понимать совокупность взаимосвязанных действий, базирующихся на стратегии развития компании, кадровом планировании, управлении служебно-профессиональным ростом, продуманном механизме адаптационных программ, циклическом и непрерывном процессе обучения персонала, повышения квалификации, формирования организационной культуры. Видим, что содержание процесса социального развития персонала является емким и достаточно сложным, требующим систематического управления со стороны руководства.

Немаловажно отметить, что сегодня управление социальным развитием персонала должно быть направлено, в том числе, и на усовершенствование корпоративной культуры внутри предприятия, включая коммуникации между сотрудниками, их взаимопомощь, соблюдение этических норм и правил, и повышение уровня моральной мотивации. Иными словами, можно утверждать то, что практическим проявлением высокого уровня социального развития персонала внутри предпринимательской структуры выступает ее командный дух, сплоченность и взаимовыгодная дружба [1]. 
По мнению специалистов (К. К. Федотовой, Т. С. Демченко) реализация продуманных социальных инструментов позволяет выстроить эффективное сотрудничество и плодотворные взаимоотношения коллектива и руководства, усилить эффект синергии принимаемых решений, раскрыть индивидуальный потенциал каждого сотрудника [2].

Согласимся с мнением А. В. Неверова, который раскрывает содержание социального развития через реализацию им таких функций, как [3]:

- управление демографическим составом предприятия через регулирование численности и состава сотрудников;

- развитие профессиональных качеств персонала, что предполагает повышение квалификации и профессиональной компетентности; улучшение общеобразовательного и культурного уровня персонала;

- совершенствование социальной инфраструктуры предприятия, включающее улучшение условий и охраны труда, обеспечение социального пакета (в том числе социального страхования и социальных гарантий), реализацию гражданских прав персонала; повышение качества жизни сотрудников;

- развитие коллектива предприятия посредством формирования и поддержания благоприятного психологического климата среди персонала, мотивации и раскрытия различных потенциалов сотрудников; повышение уровня удовлетворенности своим трудом у сотрудников;

- улучшение организационной этики, формирование принципов социальной справедливости на предприятии.

Считаем, что реализация вышеуказанных функций позволит привлечь и удержать более квалифицированных и талантливых сотрудников, улучшить эффективность профессионального взаимодействия в коллективе и, соответственно, повысить эффективность работы персонала и предприятия в целом.

Однако, стоит отметить, что сегодня, к сожалению, большинство современных предприятий не до конца осознают важность управления социальным развитием персонала, что является одной из основных причин финансовых неудач самого предприятия и порой неэффективности реализации государственных и муниципальных задач и реформ. Опыт успешных компаний, в которых управление персоналом - системный, продуманный и высокоорганизованный процесс, доказывает, что выиграть в конкурентной борьбе возможно только лишь посредством финансирования развития своего персонала, в том числе социального развития.

Справедливой, по нашему мнению, является точка зрения М. А. Эскиева и М. Р. Айсханова, считающих, что задачи по социальному развитию предприятия можно объединить в две основные группы: направленные на формирование социальных условий труда и на создание и преобразование социальной инфраструктуры [4].

В данном контексте стоит отметить, что под социальными условиями труда мы понимаем совокупность таких категорий как социальная значимость конкретной профессии и должности, сформированный социальнопсихологический климат: как в трудовом коллективе, так и на предприятии в целом, наличие коллективных традиций, корпоративной культуры, эффективность системы деловых взаимодействий и норм деловой активности.

Для реализации социальных условий труда требуется соответствующая социальная инфраструктура. Она может включать спортивные площадки, зоны отдыха, библиотеки, бассейн, столовые и кафе на территории компании, поликлиники, детские сады, летние лагеря для детей сотрудников, общежития и многое другое.

Продуктивность управления социальным развитием персонала предприятия во многом зависит и от качества организации социальной инфраструктуры.

Отметим, что важнейшими инструментами управления социальным развитием персонала предприятия выступают:

- определение и коррекция негативных психологических факторов;

- управление конфликтами;

- корпоративная культура компании;

- социально-психологическая подготовка менеджеров и руководителей;

- маркетинговые и социально-психологические исследования рабочего персонала;

- внутренний маркетинг персонала.

С целью обеспечения эффективности управления социальным развитием персонала рекомендуется приглашение психолога, реализация консультативной работы которого будет состоять в улучшении социальнопсихологического климата и недопущении конфликтных ситуаций. С целью достижения результативности управления социальным развитием персонала в коллективе целесообразно проводить тренинги, посредством 
которых осуществлялось бы обучение членов коллектива и руководителей высокой культуре взаимодействия и общения. Например, сегодня наиболее популярными и эффективными являются такие их формы, как поведенческий, ролевой, видео-тренинг и др.

В конечном итоге, управление социальным развитием персонала предприятия направлено на преодоление тех трудностей, с которыми сталкиваются управленцы при формировании мотивационной модели, контроля и организации труда [5]. Так развивается и новая социальная политика предприятия.

Продуманные, запланированные и своевременно реализованные инструменты управления социальным развитием персонала обеспечивают компании конкурентные преимущества в лице главного стратегического ресурса - персонала. Лояльные и нацеленные на результат сотрудники в свою очередь удовлетворяют потребности компании в финансовой устойчивости и стабильном росте.

В заключение отметим, что в современных условиях функционирования крупных компаний процесс управления социальным развитием персонала является неотъемлемым инструментом управления. Кроме того, данный инструмент имеет настолько весомый положительный результат и создает эффект для коммерческих предприятий, что его игнорирование выступает значимым фактором проигрыша в конкурентной борьбе. Исходя из этого, практическим заданием отечественных предприятий является не только применение элемента управления социальным развитием рабочего персонала, но и процесс его постоянного усовершенствования, что невозможно без финансовых вложений и затрат.

\section{Библиографический список}

1. Мясникова, С. В., Конарева, А. А. Социальное развитие персонала как одно из направлений корпоративной социальной ответственности // Дни науки - 2018: сб. матер. Всеросс. науч.-практ. конф., Новгородский филиал РАНХиГС. - 2018. C. 217-221.

2. Неверов, А. В. Роль оценки персонала в социальном развитии организации // Труд и социальные отношения. - 2013. № 2. - C. 38-45.

3. Соболева, Ю. П., Карпова, Т. В. Управление социальным развитием персонала предпринимательских структур // Обеспечение устойчивого развития регионов в пространственной структуре экономики России: сб. науч. тр. Нац. (Всеросс.) науч.-практ. конф. - 2018. - С. 164-167.

4. Федотова, К. К., Демченко, Т. С. Управление социальным развитием персонала в организации с помощью коррекции организационного поведения сотрудников // Новое поколение. - 2017. - № 14-2. - С. 354-358.

5. Эскиев, М. А., Айсханов, М. Р. Социальное развитие персонала организации // Молодой ученый. - 2016. - № 10. C. $941-942$.

\section{References}

1. Myasnikova S. V., Konareva A. A. Sotsial'noe razvitie personala kak odno iz napravlenii korporativnoi sotsial'noi otvetstvennosti [Social development of staff as one of the areas of corporate social responsibility]. Dni nauki-2018: sb. mater. Vseross. nauch.prakt. konf. Novgorodskii filial RANKhiGS [Days of science - 2018: collection of proceedings of the All-Russian scientific and practical conference. Novgorod branch of the Russian Academy of National Economy and Public Administration], 2018, pp. 217-221.

2. Neverov A. V. Rol' otsenki personala v sotsial'nom razvitii organizatsii [The role of personnel assessment in the social development of the organization]. Trud i sotsial'nye otnosheniya [Labour and Social relations], 2013, no. 2, pp. 38-45.

3. Soboleva Yu. P., Karpova T. V. Upravlenie sotsial'nym razvitiem personala predprinimatel'skikh struktur [Management of social development of personnel of business entities]. Obespechenie ustoichivogo razvitiya regionov v prostranstvennoi structure ekonomiki Rossii: sb. nauch. tr. Nats. (Vseross.) nauch.-prakt. konf. [Ensuring sustainable development of regions in the spatial structure of the Russian economy: collection of scientific papers of the National (All-Russian) scientific and practical conference], 2018, pp. 164-167.

4. Fedotova K. K., Demchenko T. S. Upravlenie sotsial`nym razvitiem personala v organizatsii s pomoshch $>$ yu korrektsii organizatsionnogo povedeniya sotrudnikov organizatsii [Managing the social development of personnel in the organization by correcting the organizational behavior of employees of the organization]. Novoe pokolenie, 2017, no. 14-2, pp. 354-358.

5. Eskiev M. A., Aiskhanov M. R. Sotsial'noe razvitie personala organizatsii [Social development of the organization's personnel]. Molodoi uchenyi, 2016, no.10, pp. 941-942. 